\title{
Anaphylactoid Shock Induced by Oral Penicillin and Resulting in Gerstmann's Syndrome
}

\author{
A. MERVYN FOX,* M.B., B.S., D.C.H.
}

Brit. med. F., 1965, 2, 206-208

No case of anaphylactoid shock due to oral penicillin has been reported hitherto in the British literature, although cases have been noted overseas. The present case, in which Gerstmann's syndrome features as a residuum of the reaction, is thus of no small clinical interest.

\section{Case Report}

A 46-year-old married woman was admitted to East Ham Memorial Hospital under the care of Dr. Harold W. Salmon on 26 June 1964. Earlier that day she had consulted her family doctor on account of severe pain at the root of the nose which had been present, together with mild malaise, for the previous week. As she had been thought previously to have suffered from sinusitis, phenoxymethylpenicillin (Distaquaine $\mathrm{V}-\mathrm{K}$ ) was prescribed.

Immediately after placing one tablet $(250 \mathrm{mg}$.) in her mouth she complained of "a terrible feeling," developed severe and generalized pruritus, and rapidly lost consciousness. Her family doctor was hurriedly summoned, and after administering nikethamide (1 ml.) he sent her to hospital.

When first seen, 45 minutes after the attack, she was unconscious, but responded to painful stimuli with purposeless movements. There was intense congestion of the head and neck, marked conjunctival injection, and swelling of the tongue. The finger tips were cyanosed. Blood-pressure was variable, and was unrecordable when she was first seen. The pulse was regular at 64 . The temperature was not taken. The limb tone tended to be flaccid and symmetrical, but all tendon jerks were elicited; the left plantar response was extensor; both pupils were constricted; no other localizing signs were obtained. The heart, lungs, and abdomen showed no clinical abrormalities.

Past History.-There had been no serious illnesses, but she had received penicillin on at least three previous occasions: in 1958 for earache, and in May and September 1960 for so-called chronic sinusitis. She is known to have suffered from asthma, "suspender dermatitis," and various non-specific dermatoses as well as psoriasis in the past. Apart from a transient episode of mild depression in 1960 there was no previous psychiatric history. She was an active housewife characterized by her friends as "always the life and soul of the party"; her pre-morbid personality was methodical and punctilious.

Investigations.-Normal cerebrospinal fluid was obtained at lumbar puncture soon after admission. The white cell count was $16,000 / \mathrm{c} . \mathrm{mm}$., with a moderate shift to the left in the neutrophils; eosinophil count was $360 / \mathrm{c} . \mathrm{mm}$. Erythrocyte sedimentation rate (E.S.R.), blood sugar, and blood urea were normal and blood culture was sterile. The urine contained no abnormality. Radiological examination of the chest, skull, and sinuses was negative. An electroencephalogram after three weeks showed low voltage with only traces of $\alpha$-activity; nine weeks after admission there were slight traces of $8-10 \mathrm{c} . / \mathrm{sec}$. $\alpha$-rhythm and intermixed, non-localized, occasional 7-8 c./sec. activity: this was interpreted as showing a mild non-specific abnormality. A sample of the patient's serum taken eight months after her admission to hospital caused degranulation of rabbit basophils in the presence of penicillin antigen which was considerably in excess of four control sera.

\section{Treatment and Progress}

When first seen she was given adrenaline $1 \mathrm{ml}$. by deep intramuscular injection, and this was thought to result in diminution of

* Lately Medical Registrar, East Ham Memorial Hospital, London. the glossal swelling. The blood-pressure was $90 / 70 \mathrm{~mm} . \mathrm{Hg}$ on arrival in the ward, and no reading lower than this was subsequently recorded.

She recovered consciousness 12 hours after admission, but for the next seven days alternated between an irritable delirium and what appeared to be a severe confusional state with periods of depression; she was incontinent of urine. The left plantar response remained extensor, but at this stage no other localizing neurological abnormalities were detected. She developed a psoriasiform rash associated with an eosinophil count of $546 / \mathrm{c} . \mathrm{mm}$. and E.S.R. of $29 \mathrm{~mm}$./ hr. which persisted with pruritus and involuntary scratching for two weeks.

Over the next four weeks there was sustained improvement, with acquisition of geographic and temporal orientation and resolution of retrograde amnesia. She became continent and co-operative. Three weeks after admission defective left/right orientation was first noted and she was found to be unable to copy the left half of symmetrical shapes; acalculia was also detected at this time.

On 14 August psychological testing ascribed her an intelligence quotient (I.Q.) on the Wechsler adult intelligence scale (W.A.I.S.) of 53 , the performance-scale quotient being 0 and the verbal quotient 63. Unawareness of some parts of her body was noted. Two weeks later formal psychological assessment confirmed that there was marked spatial difficulty, nominal aphasia, parital loss of left/right orientation, agraphia without alexia, and a degree of acalculia. At this time some functional overlay was suspected, but on reassessment 11 weeks after the initial episode all the features attributed to overlay had disappeared and she was left with a full-scale I.Q. of 73. The residual impairment was now well defined, and consisted of acalculia, finger agnosia, apraxia, left/right and general body disorientation, and a moderate nominal aphasia. Four weeks later there was no appreciable change.

From the time she had become ambulant she had been encouraged to play a part in the domestic activities of the ward, and had been observed, retrained in learned skills, and encouraged in an occupational therapy department. Initially her amnesia, apraxia, and spatial disorientation had made household tasks difficult and even dangerous: 13 weeks after the onset of her illness she was narrowly prevented from pouring boiling water through a colander held in her cupped hand; but two weeks later she was thought able to manage her home with the help of her sisters and supervision from a psychiatric social worker.

Seventeen weeks after admission she.was seen in consultation with Dr. Macdonald Critchley, who confirmed that she presented the picture of parietal-lobe damage, probably bilateral, with a Gerstmann syndrome, constructional apraxia, and a bilateral idecmotor apraxia.

On 18 December the I.Q. was found to have risen to 91 on the verbal and 53 on the performance scale, giving a full quotient (W.A.I.S.) of 73. There was still some nominal aphasia and difficulty with spatial relationships and tests involving arithmetic. She was seen in the out-patient department on 3 February 1965, when there was still finger agnosia, a degree of acalculia, and inability to copy or construct the left half of twodimensional figures or to write anything except her name. No gross neurological abnormalities were found. The patient expressed the opinion that she was "right back to normal," although she agreed that she was unable to check change given her while out shopping; she was able to perform all her domestic tasks and was conscious of no sort of impairment. Around her neck she wears a medallion recording that she has suffered penicillin-induced anaphylactoid shock, with the name of the hospital and her case number for the benefit of unbelievers. 


\section{Discussion}

\section{Penicillin Anaphylaxis}

Within a decade of the introduction of penicillin into clinical practice the first case of an anaphylactoid reaction had been reported (Cormia, Jacobsen, and Smith, 1945), and eight years later Welch, Lewis, Kerlan, and Putnam (1953), in a survey of the records of 95 hospitals in the United States, totalling 51,000 beds, disclosed 59 anaphylactoid reactions to penicillin with 19 deaths. A later survey of 800 hospitals over a four-year period disclosed 793 cases of anaphylactoid shock with 72 deaths, a mortality of $9 \%$. No fewer than 49 of these reactions were to oral preparations (Welch, Lewis, Weinstein, and Boeckman, 1957). None of these cases is described individually, but Batson (1960) reviewed the literature, finding detailed descriptions of 26 cases of anaphylactoid shock induced by oral penicillin, to which he added two further cases of his own. At least one early case (Fliesser and Ramey, 1956) was omitted from this series, and subsequently there have been four detailed descriptions in English (Todd, 1960 ; Krapin, 1962 ; Coates, 1963) and several in foreign language publications; it is therefore not proposed to enumerate fully all known cases of what is clearly a far from rare occurrence. The possibility of such severe reactions to oral penicillin is not widely known among doctors in this country and seems to be insufficiently stressed in standard textbooks and undergraduate teaching.

Penicillin anaphylaxis is an example of the immediate type of allergic response with reaction of serum antibodies to proteinbound derivatives of the drug, probably the penicilloyl grouping ; the immunochemical basis of penicillin allergy has recently been reviewed by Parker (1964) and will not be further discussed here.

The symptomatology of the published cases is fairly constant. Unconsciousness, skin reactions, pruritus, facial oedema, and cyanosis-as displayed in the present case-are commonly found, often in combination with gastro-intestinal disturbance, respiratory distress, convulsions, chest pain, and other constitutional effects. Hypotension is a general finding. The time interval that frequently occurs between the onset of trivial symptoms and the establishment of a life-threatening state is stressed by Krapin (1962). The early warning may be given by the development of reddening of the bulbar conjunctiva, slight dizziness or faintness, and tingling of the skin (Nemser, 1954). Deep-red discoloration of the skin is not infrequent (Todd, 1960 ; Krapin, 1962), and the severe pruritus is given prominence in several accounts, notably those written by physicians of their own experiences (Weinstock and Albin, 1956; Nudelman, 1956 ; Lewis, 1957), wherein striking similes are used to express the discomfort: "a million needles pricking deeply into the skin"; "itching as though I had a thousand fleas." This severe pruritus was a feature of the present case.

Angor animi and cacogeusia are features of reported cases, and on one occasion (Calvert and Smith, 1955) a mild immediate reaction to oral penicillin preceded by two weeks the injection which provoked a severe anaphylactoid reaction: this represents the ideal interval between first and second exposures for the development of anaphylaxis, and it is disturbing that in this instance the patient mentioned the earlier mild incident but was ignored by the administering doctor. Prior exposure to penicillin is not, however, necessary for development of the immediate response, and Strauch, Byrd, and Eng (1954) reported anaphylactoid shock in response to the first injection of penicillin into a 6-week-old infant. In these days it becomes increasingly difficult to deny the possibility of previous exposure to penicillin, which is used extensively in medical and veterinary practice. Lewis (1957), in a review of the literature, quotes the occurrence of anaphylactoid shock after instillation of penicillin into wounds and sinuses as well as to penicillin aerosol, eye ointment, lozenges, and tablets.

Clinical diagnosis of penicillin-induced anaphylaxis depends largely upon the physician's awareness of the condition and a history of recent ingestion or administration of the drug, and this should be the subject of direct inquiry in obscure cases of collapse and shock. Prospective diagnosis of penicillin sensitivity is discussed by Parker (1964). The status of the basophil degranulation technique as used retrospectively in this patient appears uncertain at present (Cruickshank, 1965).

The mode of treatment employed in the reported cases clearly depends on the availability of therapeutic agents; adrenaline, as used in the present case, is a common choice, but hydrocortisone, penicillinase, antihistamines, and aminophylline have all been used. Not one has emerged as a drug of choice. Adrenaline and hydrocortisone are recommended by Calnan (1964) in a recent symposium, while in discussion Frankland (1964) is quoted as saying that anti-inflammatory steroids are of no help in acute anaphylactoid reactions.

\section{Penicillin and the Central Nervous System}

Experimental and clinical evidence leaves no doubt that the central nervous system is vulnerable to penicillin as a pure substance in sufficient concentration, and convulsions and peripheral neuropathy have been reported after contact with nerve tissue as in intrathecal and intraventricular injection or administration on to the cerebral cortex (Welch and Lewis, 1951). Psychiatric disturbances attributable to penicillin are reviewed by Cohen (1963), who mentions two distinct syndromes: firstly, an acute psychotic reaction during or immediately after intramuscular injection, associated with little or no alteration of vital signs but considerable sensory and mental aberration; and, secondly, an acute toxic psychosis associated with obvious allergic phenomena. $\mathrm{He}$ also reports two cases of irreversible brain damage due to anaphylactoid shock and resulting anoxia, and there can be little doubt that the present case belongs in this category, although having some features in common with the group of acute toxic psychoses.

\section{Gerstmann's Syndrome}

The coexistence in the same patient of finger agnosia, agraphia, acalculia, and left/right disorientation was first noted in 1888 in a woman recovering from eclampsia and post-partum haemorrhage by Professor Jules Badal, a Bordeaux ophthalmologist (Gayral, 1963), but was not brought to general notice until the description by Gerstmann (1924) of an arteriosclerotic case. The syndrome has achieved popular renown on account of its bizarre features, and has acquired a reputation for a high degree of localizing significance. Critchley (1953) states that the syndrome can reasonably be interpreted as a sign of parietal disease in general rather than as specifically indicating a lesion of the angular gyrus.

Benton (1961) quotes Gerstmann (1957) as affirming that in pure form the coexistence of the four cardinal signs does indicate a highly specific focal lesion involving "that nodal area which corresponds to the angular gyrus in its transition to the second occipital convolution," but demonstrated in a detailed study of 100 patients with generalized and parietal damage that the combination regarded by Gerstmann as specific was no more likely to emerge than any other combination of four findings selected out of visual amnesia, colour agnosia, general mental impairment, constructional apraxia, and the four Gerstmann components. He notes that the syndrome has been reported in isolated frontal-lobe damage, and concludes that the syndrome is a myth born out of observer bias and imprecise examination, and serves only to draw attention to the dominant parietal lobe. In a similar study Heimburger, Demyer, and Reitan (1964) also conclude that the syndrome cannot be regarded as a discrete entity, and find that when two, three, or four of the components coexist lesions are never restricted to the angular gyrus but tend to be widespread over the parietal, temporal, and occipital lobes. Full and precise examination rarely permits the Gerstmann syndrome to exist in a pure state, 
and usually, as in the present case, constructional apraxia will be detected with or without ideational apraxia, alexia, or sensory agnosia.

Interpretation of Gerstmann's syndrome as an easily demonstrated and memorable pointer to diffuse cerebral damage accords well with this case, where there is no reason to suspect a highly focal lesion. Gerstmann's syndrome does not seem to have been reported in association with penicillin anaphylaxis. There can be little doubt that in this case the curious neurological manifestations were secondary to hypotension and cerebral oedema associated with anaphylactoid shock.

\section{Summary}

An anaphylactoid reaction to oral penicillin in a 46-year-old woman is described: after hours of unconsciousness and weeks of confusion she was left with a residual Gerstmann's syndrome. These reactions are less rare than is generally supposed. Symptomatology, treatment, diagnosis, and mechanism are discussed, and some of the relevant literature is briefly reviewed.

Thanks are due to Dr. Harold W. Salmon for permissien to publish this case and for help in the preparation of this report; to Dr. C. N. D. Cruickshank, of the M.R.C. Unit for Research on the Experimental Pathology of the Skin, for performing investigations on the serum of this patient; to Miss E. M. Best, of Runwell Hospital, for the psychological assessments; and to Miss I. L.
Brooks, of the Occupational Therapy Department of St. Mary's Hospital for Women and Children, for her detailed reports on the successful rehabilitation of this patient.

\section{REFERENCES}

Batson, J. M. (1960). New Engl. 7. Med., 262, 590.

Benton, A. L. (1961). F. Neurol. Neurosurg. Psychiat., 24, 176.

Calnan, C.D. (1964). Postgrad. med. F., 40, Suppl. p. 152.

Calvert, R. J., and Smith, E. (1955). Brit. med. F., 2, 302.

Coates, W. H. (1963). Med. F. Aust., 1, 967.

Cohen, S. B. (1963). F. Amer. med. Ass., 186, 899.

Cormia, F. E., Jacobsen, L. Y., and Smith, E. L. (1945). Bull. U.S. Army Med. Dep., 4, 694.

Critchley, Macdonald (1953). The Parietal Lobes. Arnold, London.

Cruickshank, C. N. D. (1965). Personal communication.

Fliesser, W., and Ramey, C. A. (1956). Illinois med. F., 110, 182.

Frankland, A. W. (1964). Postgrad. med. F., 40, Suppl. p. 166.

Gayral, M. L. (1963). F. méd. Bordeaux, 140, 1719.

Gerstmann, J. (1924). Wien. klin. Wschr., 37, 1010.

- (1957). Neurology (Minneap.), 7, 866.

Heimburger, R. F., Demyer, W., and Reitan, R. M. (1964). F. Neurol. Neurosurg. Psychiat., 27, 52.

Krapin, D. (1962). New Engl. F. Med., 267, 820.

Lewis, G. W. (1957). Brit. med. F., 1, 1153.

Nemser, H. S. (1954). N.Y. St. F. Med., 54, 1514

Nudelman, P. L. (1956). Northw. Med. (Seattle), 55, 1074.

Parker, C. W. (1964). Postgrad. med. 尹., 40, Suppl. p. 141.

Stauch, J. H., Byrd, W. C., and Eng. G. O. (1954). Tex. St. f. Med., $50,699$.

Todd, L. P. (1960). Calif. Med., 93, 230.

Weinstock, I., and Albin, M. B. (1956). New York St. 7. Med., 56, 1825. Welch, H., and Lewis, C. N. (1951). Antibiotic Therapy. Baillière, Tindall and Cox, London.

Kerlan, I., and Putnam, L. E. (1953). Antibiot. and Chemother., 3, 891 .

Weinstein, H. I., and Boeckman, B. B. (1957). Antibiot. med., Brit. Ed. 4, 800 .

\title{
Skin Sensitization to Remiderm and Cross-sensitization to Hydroxyquinoline Compounds
}

\author{
C. F. ALLENBY,* M.R.C.P.
}

Brit. med. F., 1965, 2, 208-209

The use of local corticosteroid preparations on the skin is increasing, and to counter skin infection antibintics and antiseptic preparations are being added more frequently. Because of epidermal sensitization to antibiotics, exemplified by the increase in neomycin sensitivity (Kirton and Munro-Ashman, 1965), and the development of antibiotic resistance, " antiseptic preparations are becoming more popular" (Vickers, 1964), and the chief of these is the hydroxyquinoline group.

This paper reports the cases of three patients who showed skin sensitization to Remiderm, which contains a new antiseptic, halquinol (Quixalin), $0.75 \%$, with $0.025 \%$ triamcinolone in either a cream or Plastibase.

In addition to sensitization to halquinol they showed crosssensitivity to related hydroxyquinoline compounds. The possibility that sensitivity may be present should be borne in mind whenever these or new related compounds are used on the skin or systemically.

\section{Case Reports}

Case 1.-A woman aged 24 showed sensitization dermatitis to Remiderm after the second application of ointment to gravitational ulcers. She had used Vioform ointment six months previously, which produced irritation.

Case 2.-A woman aged 31, after using Remiderm for gravitational dermatitis, immediately had acute exacerbation with generalized spread of dermatitis. She had used Vioform two years previously.

* Department of Dermatology, the Radcliffe Infirmary, Oxford.
Case 3.-A man aged 58 had gravitational dermatitis which was made worse by Remiderm. He had used Vioform two years previously.

Investigations.- Halquinol contains three derivatives of hydroxyquinoline. Two of these, 5,7-dichloro-8-hydroxyquinoline and 5-chloro-8-hydroxyquinoline, were skin-tested, and all three patients showed strongly positive patch tests to them and to halquinol after 24 hours (see Table). The third constituent (less than $4 \%$ ), 7 chloro-8-hydroxyquinoline, was not available.

\begin{tabular}{|c|c|c|c|}
\hline & Case 1 & Case 2 & Case 3 \\
\hline $\begin{array}{l}\text { Halquinol } \\
\text { 5,7-dichloro-8-hydroxyquinoline } \\
\text { 5-chloro-8-hydroxyquinoline } \ldots \\
\text { Steroxin (chlorquinaldol) } \\
\text { Vioform } \\
\text { Diodoquin (di-iodohydroxyquinoline) } \\
\text { Quinolor } \\
\begin{array}{l}\text { Qu } \\
\text {. . . . }\end{array}\end{array}$ & $\begin{array}{l}++++ \\
++++ \\
++++ \\
+++ \\
+++ \\
+++ \\
++++\end{array}$ & $\begin{array}{l}+++ \\
+++ \\
+++ \\
++ \\
++ \\
++ \\
++\end{array}$ & $\begin{array}{r}++ \\
+++ \\
+++ \\
++ \\
++ \\
++ \\
+++\end{array}$ \\
\hline
\end{tabular}

All compounds $0.75 \%$ in hydrous eucerin, except Quinolor. Grading of result according to Schwartz et al. (1957).

No patient had a history of infantile eczema, and patch tests to Plastibase, cream base (Squibb), $0.025 \%$ triamcinolone, tincture of iodine, and hydrous eucerin (Smith and Nephew) were negative at 48 hours and showed no delayed results.

Cross-sensitization to related compounds was also demonstrated, the structure of 8 -hydroxyquinoline (see Formula) being the common factor.

Formulae are: Diodoquin, 5-7-di-iodo-8-hydroxyquinoline; Vioform, 7-iodo-5-chloro-8-hydroxyquinoline; Steroxin 